\title{
A negociação dos mal-entendidos em interações no Twitter
}

José Gaston Hilgert"

Débora Cristina Longo Andrade*

\section{Resumo}

Propusemo-nos, neste trabalho, a identificar mal-entendidos em um corpus constituído de mensagens postadas em um ambiente da internet. Procuramos descrever como os interlocutores, por meio de estratégias linguístico-discursivas, operam na organização do texto virtual escrito, com o intuito de monitorar os equívocos de compreensão, de modo a prosseguirem na abordagem do tema em pauta na comunicação. Para o desenvolvimento deste estudo, foram selecionadas conversações digitais, ou melhor, tweets produzidos por perfis qualificados como figuras públicas em interação com seus seguidores, na rede social Twitter. Na análise do corpus, observamos que, no acontecimento do mal-entendido, os interlocutores se utilizam de procedimentos metadiscursivos para tentar solucionar esses desvios de compreensão que põem em risco o sucesso da interação. Para fundamentar este trabalho, recorremos aos pressupostos teóricos advindos da Etnometodologia Conversacional e da Linguística Interacional. Pretendemos demonstrar, com este estudo, que os interlocutores mobilizam diferentes operações sobre o próprio ato de dizer, na tentativa de negociar os mal-entendidos, tendo em vista as- segurar a compreensão, bem como um mínimo de harmonia em suas práticas discursivas no contexto digital.

Palavras-chave: Interação. Mal-entendido. Negociação. Compreensão. Twitter.

\section{Introdução}

O desdobramento bem-sucedido de uma interação linguística, sejam quais forem os propósitos comunicacionais que a motivem, pressupõe a necessidade de compreensão entre os interlocutores. Nessa perspectiva, pode-se dizer que, numa relação comunicativa, o propósito primeiro do enunciador é assegurar que seu enunciado seja compreendido pelo destinatário, sem o que os objetivos da interação ficarão comprometidos. Como

* Professor de Linguística do Programa de Pós-Graduação em Letras da Universidade Presbiteriana Mackenzie. E-mail: gastonh@uol.com.br

** Mestrado em Língua Portuguesa pela Pontifícia Universidade Católica de São Paulo, Brasil (2015). Pesquisadora da Universidade Presbiteriana Mackenzie, Brasil. E-mail: debora.cla@terra.com.br/0000-00018607-2029. E-mail: gersont@upf.br

Data de submissão: set. 2020 - Data de aceite: nov. 2020 http://dx.doi.org/10.5335/rdes.v16i3.11510 
professores, tratamos predominantemente de questões de compreensão quando, no processo de ensino-aprendizagem, ensinamos os alunos a escrever textos com clareza e coerência, ou quando, em atividades de leitura e interpretação, os orientamos nos meandros responsáveis pela produção dos sentidos.

É bem menos comum que a compreensão seja objeto de estudo e análise numa conversa. Até porque as conversas cotidianas, sejam nas interações face a face, sejam nas que ocorrem por meio das redes sociais, costumam evoluir de forma tão fluente e fácil e, digamos, de forma tão inconsciente quanto o ato de respirar. Respiramos o tempo todo sem pensarmos neste ato tão essencial à vida. Só tomamos consciência dele quando nos defrontamos com problemas de respiração. Assim acontece com a compreensão nas conversas. Predomina, em seu desdobramento, no dizer Deppermann (2008), a compreensão "silenciosa", isto é, sem que os interlocutores em interação voltem a ela atenção explícita. No entanto, quando no curso conversacional surge um problema de compreensão, este se torna, por um momento, tema da conversa, isto é, objeto de atenção dos interlocutores até encontrarem uma solução para ele. Em outras palavras, com o problema de compreensão interrompe-se o fluxo temático da conversa, que, em princípio, só será retomado com o problema resolvido.
É da compreensão em conversas que tratará o presente texto, mais especificamente de problemas de compreensão que ocorrem em conversas no Twitter. Escolhemos este objeto de estudo, porque estamos convictos de que a formação de professores de língua precisa, atualmente, em razão da presença incontornável das chamadas redes sociais na sociedade, incorporar em seu processo o estudo das manifestações linguísticas nessas redes, seja como objeto teórico de investigação, seja como ponto de partida para o desenvolvimento de práticas de letramento e multiletramento. Nessa perspectiva, privilegiaremos aqui o enfoque teórico, na medida em que tentaremos descrever o monitoramento dos mal-entendidos em interações no Twitter, destacando sua dinâmica organizacional, os fatores que os desencadeiam, os modos em que são denunciados e resolvidos, e as atitudes linguístico-sociais dos interlocutores em sua abordagem. Com base nesses aspectos apontaremos também, ao final, possibilidades desses conhecimentos para gerar propostas de ensino.

Desenvolveremos o trabalho de acordo com os seguintes tópicos: a natureza da oralidade nas redes sociais; a natureza da compreensão nas enunciações; 0 problema de compreensão como instância inerente à construção dos sentidos; os mal-entendidos; os mal-entendidos em interações no Twitter. 


\section{A natureza da oralidade nas redes sociais}

Já deixamos explícito nas considerações introdutórias que entendemos por conversas tanto as interações face a face do cotidiano, quanto as que ocorrem nas redes sociais, como, por exemplo, no Twitter, no WhatsApp, no Facebook. Poderá o leitor se perguntar se não é demasiadamente abrangente essa concepção, já que as conversas propriamente ditas são de caráter oral, e as interações nas redes sociais se realizam pela escrita. Efetivamente, se considerarmos sua natureza medial, manifestações orais e escritas se opõem dicotomicamente. No entanto, se adotarmos o critério conceptual para definir a oralidade e a escrita, veremos que as interações nas plataformas referidas tanto se identificam com os diálogos orais que não só podem ser denominadas de conversas, mas também são passíveis de serem analisadas e descritas à luz dos fundamentos teóricos dos estudos conversacionais.

Buscamos nos autores alemães Koch e Oesterreicher $(2007,2011,2016)$ a base teórica para definir esse critério conceptual. Reconhecem eles que a classificação dos gêneros discursivos, com base, unicamente, em sua caracterização medial - distinguindo gêneros medialmente falados (de caráter fônico) de gêneros medialmente escritos (de caráter gráfico) - é simplista e pouco produtiva como princípio analítico-interpretativo dos gêneros. Incorporam, então, essa distinção em uma proposta que distingue entre oralidade medial e conceptual e entre escrita medial e conceptual. Por medial, continuam os autores considerando as representações gráfica e fônica dos textos. A inovação está no caráter conceptual da oralidade e da escrita. Resumidamente, pode-se dizer que entendem por conceptual a percepção que os usuários da língua têm, no âmbito de suas práticas sociais, de um gênero ser, com base em suas características de produção e construção, de caráter oral ou escrito, independentemente de sua expressão medial. Quanto mais o gênero evoca a fala, mais ele é percebido como conceptualmente falado; quanto mais seus traços lembram a escrita, mais ele é reconhecido como conceptualmente escrito. Nessa perspectiva, os gêneros discursivos praticados numa sociedade se distribuem num continuum que se estende do polo da oralidade prototípica (por exemplo, uma conversa fortuita) ao polo da escrita prototípica (por exemplo, um texto jurídico). A questão não é mais saber se determinado gênero é oral ou escrito, no sentido medial, mas sim, identificá-lo quanto ao grau de oralidade ou de "escrituralidade" que o caracteriza, no continuum, em relação aos polos prototípicos. Nesse sentido fica evidente, então, que a posição de uma interação no WhatsApp ou no Twitter, nesse continuum, está muito próxima de 
uma conversa face a face, tanto pelas características composicionais, temáticas e estilísticas do gênero (BAKHTIN, 2003), quanto pela percepção de oralidade que dele tem o usuário da língua em suas práticas sociais. É por essa razão que nos sentimos autorizados a considerar a interação no Twitter como uma conversa e, em decorrência, a assumir as categorias teóricas da análise linguística da conversação para orientar este estudo.

\section{A natureza da compreensão nas enunciações}

É princípio basilar da enunciação que toda produção discursiva é $a c ̧ a ̃ o$ conjunta dos interlocutores envolvidos. Esse entendimento está fundamentado no preceito da coenunciação, segundo o qual, no dizer de Fiorin (2003, p. 163), "o enunciatário, como filtro e instância pressuposta no ato de enunciar, é também sujeito produtor do discurso, pois o enunciador, ao produzir um enunciado, leva em conta o enunciatário a quem ele se dirige". Levar em conta o enunciatário implica que o enunciador contempla, na enunciação, o que sabe ou supõe saber dele, baseado tanto em pressupostos socioculturais quanto em conhecimentos concretos e específicos que dele tem. Nesse sentido, também o enunciatário realiza o seu fazer interpretativo orientado por um simulacro que constrói do enunciador. Por isso, enunciador $e$ enunciatário constituem o sujeito da enunciação, assumindo ambos, nessa instância complexa, a autoria da construção dos sentidos.

A coenunciação se torna particularmente explícita nas interações orais, marcadas por intensa alternância de turnos, como é o caso das conversas face a face e, semelhantemente, as que se desenrolam no Twitter. Nelas o detentor do turno, o enunciador, constrói o seu enunciado - escolhendo palavras, estruturando a sintaxe, especificando sentidos, repetindo, insistindo, parafraseando, corrigindo -, determinado por sinalizações do interlocutor, no aqui e agora do desdobramento interacional. É nessa perspectiva que a conversação constitui uma ação conjunta com características bem específicas. Trata-se, segundo Clark (1996, p. 18), de "uma ação realizada por um conjunto de pessoas, agindo em coordenação umas com as outras". Em síntese, na interação conversacional, as ações individuais do falante e do ouvinte não são ações autônomas, porém participativas que, no desdobramento conversacional, se coordenam de forma a constituírem uma única ação conjunta.

É por meio desse desdobramento de determinações mútuas que os interlocutores, na medida em que vão produzindo sentidos, vão construindo a compreensão entre si. A compreensão e a interpretação nas interações não é, então, um fazer 
restrito ao destinatário de um turno, realizado separadamente da enunciação do destinador. Este, ao levar em conta o interlocutor a quem se dirige, já inscreve na enunciação as condições da compreensão, os parâmetros da interpretação. A instância da compreensão é, então, inerente à da enunciação. E enunciador e enunciatário, por serem o sujeito da enunciação, constituem também o sujeito da compreensão.

\section{O problema de compreensão como instância inerente à construção dos sentidos}

A preocupação dos interlocutores em assegurarem a intercompreensão, no desdobramento da interação, não só se revela quando o ouvinte denuncia dificuldades de compreensão em relação ao todo ou a partes da manifestação do falante, ou quando a resposta do ouvinte a um turno do falante é por este percebida como sendo um mal-entendido. Por reconhecer que o desdobramento da ação comunicativa está sujeito a toda ordem de turbulências de interpretação e compreensão (SCHEGLOFF; JEFFERSON; SACKS, 1977; FIEHLER, 2002), o falante adota estratégias preventivas de diferentes naturezas linguístico-discursivas, que se impõem, cá ou lá, por razões diversas, na construção do turno, para evitar que o ouvinte tenha problemas de com- preensão e, assim, assegurar sintonia entre enunciação e interpretação. Nas palavras de Fiehler (2002, p. 20), tais estratégias têm função "profilática”. São procedimentos recorrentes nesse sentido paráfrases, repetições, exemplificações, autocorreções e outras estratégias metadiscursivas, por meio das quais o falante se antecipa a fatores que possam gerar problemas de compreensão de alguma ordem. Observem-se estes segmentos conversacionais:

F1 e como é que vocês vêem tudo isso nesse sistema todo o operário [quer dizer aquele que vive do salário mínimo?] ...

F2 olha esse é o pobre-coitado ... está?

F1 eu nem sei como é que vive (HILGERT, 2009, p. 123-124).

$* * * * *$

F1 vocês acham assim que na sociedade há alguma profissão [que:: seria proibida assim às mulheres] [que as mulheres não devem ter] [que vocês acham que não poderia exercer?]

F2 depende da mulher eu estive pensando mesmo ontem quando... (HILGERT, 2009, p. 131).

$* * * * *$

F1 e:: a senhora acha assim que:: ... (que) [por exemplo:: ... trabalhar em determinado tipo de serviço mesmo que ganhe muito] é perder tempo [no sentido de que:: (se) morre mais cedo (essas coisas)]?

F2 se:: se o indivíduo... indivíduo na questão de pessoa... gosta do serviço... que vá avante... é uma coisa muito subjet/ subjetiva... (HILGERT, 1997, p. 161). 
$\mathrm{Na}$ primeira passagem, o uso do termo "operário", sem outras especificações, poderia levar a uma compreensão demasiadamente ampla do sentido da pergunta. Fazendo a correção parafrástica, "quer dizer aquele que vive do salário mínimo", o falante se antecipa a um possível problema de compreensão. No segundo, essa antecipação acontece por meio de dupla retomada parafrástica: o segmento "que:: seria proibida às mulheres" é parafraseado por "que as mulheres não devem ter" e por "que vocês acham que não poderiam exercer". Finalmente, no terceiro segmento, o sentido da pergunta vem explicitado e, assim, assegurado na forma de uma exemplificação - "por exemplo::... trabalhar em determinado tipo de serviço mesmo que ganhe muito é perder tempo". Além disso, a expressão "perder tempo" ganha sentido restrito quando o falante prossegue, dizendo "no sentido de que:: (se) morre mais cedo". Evita, dessa forma, que o interlocutor lhe retruque com uma pergunta do tipo "O que você quer dizer com 'perder tempo'?".

Esses breves exemplos revelam, no dizer de Fiehler (2002, p. 8), "que a compreensão aparece como algo que a qualquer momento corre risco, pode falhar, e que a comunicação por isso exige dos parceiros uma cuidadosa observação e um trabalho colaborativo, a fim de chegar, na medida exigida, à compreensão". Nessa ótica, a comunicação pode ser definida como, no dizer do mesmo autor, "um esforço alternado imprescindível em favor de uma compreensão em constante risco".

Mas, apesar dessa atenção preventiva, muitos problemas de compreensão efetivamente se instalam no desdobramento da interação, determinados pelos mais variados e surpreendentes fatores que vão desde imprecisões de sentido, impropriedades lexicais, complexidades sintáticas, inconsequências argumentativas, até a diversidade dos padrões linguísticos em uso na interação, a disparidade de saber que os interlocutores têm do tema em pauta na interação, a assimetria no grau de conhecimento que eles têm um do outro, e até diferenças culturais e ideológicas. Em suma, o simples fato de serem pessoas diferentes em interação põe os interlocutores diante da constante possibilidade de se depararem com problemas de compreensão de toda ordem.

Segundo Bazzanella e Damiano (1999, p. 832), esses problemas revelam-se como "fases do processo de construção da compreensão", ou, no dizer de Kindt (2002, p. 22), eles "podem significar um estágio intermediário na construção da compreensão". Essas considerações levam a conceber o problema de compreensão como instância inerente ao processo de construção dos sentidos e da compreensão, fazendo parte, portanto, de um continuum, em que a busca de com- 
preensão pode partir de situações de total ausência dela e passar por diferentes estágios ou graus de não compreensão.

Conforme já adiantamos, no início deste tópico, identificam-se, nas interações, dois tipos de problemas: um constituído pelos que chamaremos de problemas em sentido específico; e outro, pelos mal-entendidos. Trataremos, brevemente, do primeiro tipo, na sequência imediata. No tópico a seguir, focalizaremos os mal-entendidos, centrando nossa atenção em sua ocorrência em interações no Twitter, objeto central deste estudo.

Consideramos problema de compreensão, em sentido específico, toda ocorrência linguístico-discursiva no turno do falante (T1) denunciada pelo ouvinte, em seu turno subsequente (T2), de conter algum problema de compreensão. É o que mostra este exemplo:

(T1) F1 então eu entendo que as crises seriam... exatamente isso... a contestação do mundo típico em que vivemos... pelo mundo atípico... característico a a cada um de nós... mas eu entendo que... esse mundo... esse mundo típico... eh:: ele é contestado a certo nível... um nível em que jamais... pelo menos é o que se vislumbra entende?

(T2) F2 e o que são o mundo típico e o mundo atípico?

(T3) F1 eu já falei o mundo típico entende? é Esse... o é o mundo em que vivemos... o mundo estratificado... um mundo tecnocrata... um mundo em que::...

(T4) F3 é a estrutura social

(T5) F1 é a estrutura social em que vivemos... em que:: ... elementos

(T6) F3

(HILGERT, 2009, p. 22-23).

$$
\text { o mundo atípico é o mundo interior }
$$

A interação envolve três interlocutores. O tema em foco em $\mathrm{T} 1$ são as crises, cuja natureza se definiria, segundo F1, pela contestação de um mundo típico por um mundo atípico. São justamente essas expressões "mundo típico" e "mundo atípico" que constituem um problema de compreensão para F2, como se pode ver em T2. Denunciado o problema, F1 procede, em T3 e T5 a explicar o que entende por esses dois mundos, no que é ajudado por F3, em T4 e em T6. Fica bem evidente nesse breve segmento interacional, primeiramente, a estrutura interacional padrão na emergência desse tipo de problema de compreensão: a) no fio da interação, F1 produz o turno de referência no qual se situa o problema de 
compreensão denunciado no turno subsequente; b) F2 produz o turno de denúncia do problema de compreensão inscrito no turno anterior; c) $\mathrm{F} 1$ produz o turno de solução do problema de compreensão denunciado por F2. A partir de então, a interação segue, dando sequência ao desdobramento temático interrompido com o surgimento e a solução do problema de compreensão. Representamos esquematicamente essa dinâmica organizacional dos turnos no Gráfico 1:

Gráfico 1 - Dinâmica organizacional dos turnos

\begin{tabular}{|l|l|}
\hline Posição 1 & •Turno de referência \\
\hline Posiçã̃o 2 & •Turno de denúncia \\
\hline Posição 3 & •Turno de solução \\
\hline
\end{tabular}

Fonte: elaboração dos autores.

Tendo já em vista a distinção a ser feita entre essa dinâmica e a que organiza os turnos em situações de mal-entendidos, destacamos que, no Gráfico 1, o problema de compreensão se inscreve na posição 1 , a denúncia ocorre na posição 2, e solução, na posição 3. Essa estrutura pode sofrer variações, sendo muito recorrente entre elas o desdobramento da solução do problema em turnos sucessivos, notadamente em situações em que um maior número de interlocutores participa da interação.

Um outro aspecto que se evidencia na passagem conversacional acima é o fato de que a busca de compreensão, na solução de problemas dessa ordem, é um trabalho interativo inerente ao processo de construção de sentidos. Por isso, a palavra "problema", neste contexto não é usada na acepção de algo que se deva evitar, mas sim, como um traço constituinte da natureza das interações informais sem planejamento prévio.

O outro problema de compreensão de que falamos é o mal-entendido. Como ele é o foco central de nosso estudo, vamos tratar dele em tópico específico, na sequência.

\section{Os mal-entendidos}

No dizer de Weigand (1999, p. 770), o mal-entendido se caracteriza como uma "forma de entendimento parcial ou totalmente divergente do que o enunciador tencionou comunicar e que poderá ser corrigida normalmente no desenvolvimento do jogo de ação dialógica". Em outras palavras, é toda e qualquer forma de compreensão total ou parcialmente desviante, manifesta por um interlocutor, em relação à expectativa de compreensão do outro. Ardissono, Damiano e Boella (1997) endossam essa concepção, preconizando que a ocorrência do mal-entendido se dá quando o ouvinte concebe uma interpretação para algum turno, a qual considera coerente do seu ponto-de-vista, mas que não é a pretendida pelo falante.

A interação a seguir, entre interlocutores no Twitter, exemplifica esse conceito. 
(T1) Usuário A: "O Boris Johnson deveria tomar vergonha na cara e pentear o cabelo. Não entendo estas pessoas que ficam descabeladas o tempo todo. Custa pentear o cabe-

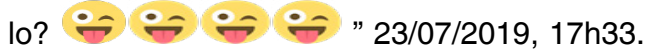
Tweet.

(T2) Usuário B: "Ô Guga quando for publicar algo desse tipo, se olhe no espelho. Vc está despenteado na foto. Jornalista dos EUA, se preocupando com isso. Me poupe." 23/07/2019, 20h58. Tweet.

(T3) Usuário A: "Meu Deus, será que vc não entendeu que eu estava brincando justamente pq sou descabelado? Inacreditável a falta de inteligência. Até coloquei o Emoji $\because$ para deixar claro que estava brincando, e me auto-depreciando, ao falar do cabelo do Boris Johnson" 23/07/2019, 21h16. Tweet.

(T4) Usuário B: "Desculpe Guga, mas, vc é um dos únicos da emissora que até consigo ouvir e sempre achei maneiro o seu cabelo. Mas achava que vc não percebia.

$\because$ Não está mais aqui quem comentou - - - 23/07/2019, 22h34. Tweet.

Disponível em: https://twitter.com/xxxxxxxx/status/1153765206461493252. Acesso em: 25 jun. 2020.

Observe-se que, em T1, o Usuário A faz uma crítica ao desalinhamento dos cabelos do Boris Johnson, primeiro ministro da Inglaterra. Em T2, o Usuário B contesta a crítica, por entender que ela é incoerente, vindo de Guga, repórter e apresentador da Rede Globo de Televisão em Nova Iorque, cuja marca também é o cabelo desgrenhado. Em T3, o Usuário A, revelando espanto (Meus Deus), deixa claro ao interlocutor, em termos até agressivos (Inacreditável a falta de inteligência), que sua leitura do enunciado é equivocada, por não ter percebido o seu caráter obviamente irônico, denunciando, assim o mal-entendido e, ao mesmo tempo, solucionando-o.

Weigand (1999), apresenta a seguinte estrutura padrão para os mal-entendidos em interações face a face, a qual, como se viu no exemplo, não é diferente em interações no Twitter.

i. Turno 1 - (A) formula seu enunciado.

ii. Turno 2 -(B), em seu enunciado, interpreta o enunciado de $\mathrm{A}$.

iii. Turno 3 - (A) denuncia o enunciado de B como um mal-entendido, mostrando que a interpretação feita não era a aguardada e fazendo a correção.

Representamos esquematicamente essa estrutura no Gráfico 2:

Gráfico 2 - Estrutura padrão para os mal-entendidos

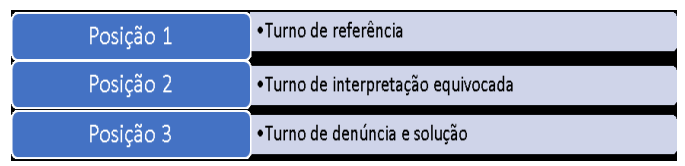

Fonte: elaboração dos autores.

Comparando o Gráfico 2 com o Gráfico 1 , verifica-se que, aqui, o mal-entendido vem inscrito na posição 2 e, lá, o problema de compreensão se inscreve na posição 1 ; neste, tanto a denúncia quanto o encaminhamento de solução do mal-entendido vêm na posição 3 , enquanto que naquele, a denúncia ocorre na posição 2 e a solução, na posição 3 . 
A constatação do "reparo em terceira posição", na dinâmica organizacional do monitoramento dos problemas de compreensão nas interações face a face, já havia sido feita (SCHEGLOFF, 1992, p. 1301), entendendo-se por reparo a ação empreendida por um participante para apontar algum desvio de compreensão evidenciado, com o intuito de que venha a ser resolvido mediante a utilização de diversos procedimentos, por exemplo, a correção e a paráfrase.

Essa estrutura interacional padrão relativa aos mal-entendidos pode sofrer variações. É muito comum, por exemplo, um turno de quarta posição, conforme atesta o exemplo acima. Em T4, o Usuário $\mathbf{B}$ encerra a sequência interacional centrada no monitoramento do mal-entendido, reconhecendo não ter percebido a ironia (mas achava que vc não percebia) e, por isso, pedindo desculpas por sua intervenção.

Os mal-entendidos surgem nas interações, por diferentes razões. Bazzanella e Damiano (1999, p. 818-821), com base na análise de um corpus do italiano falado, classificam as causas da ocorrência de mal-entendidos em relação a duas dimensões:

i. o nível em que esse fenômeno pode ocorrer (fonético, sintático, lexical, semântico e pragmático);

ii. os fatores que o desencadeiam, denominados pelas autoras de "gatilhos", tais como: "estrutu- rais" (distúrbios junto ao canal comunicativo; ambiguidades lexicais ou sintáticas, similaridades entre elementos do código linguístico, distúrbios causados pelo uso de uma língua estrangeira); relacionados ao "falante" (problemas quanto à prosódia, atos de fala indiretos, indeterminação, anacoluto, entre outros); relacionados ao "ouvinte" (lacunas no conhecimento enciclopédico, construção de falsas inferências) e/ou relacionados à "interação entre os interlocutores" (diferenças culturais, diferenças entre os estilos comunicativos, conhecimentos não compartilhados).

Cada estudo específico vai evidentemente identificar outros desencadeadores de mal-entendidos pelo simples fato de eles serem tão imprevisíveis quanto as razões que nos impelem a negociar sentidos no desdobramento das interações, em nossas práticas sociais.

Quanto aos procedimentos de solução dos mal-entendidos, predominam as intervenções metadiscursivas em que, segundo Koch (2009), o locutor da terceira posição, além de denunciar o mal-entendido exposto na segunda, retoma seu enunciado da primeira posição, repetindo-o no todo ou em parte, parafraseando-o, corrigindo-o, fazendo ajustes e modalizações. Dentre as estratégias metadiscursivas, a autora destaca: 
i. estratégias metaformulativas, por meio das quais o enunciador procede a reformulações, com 0 intuito de sanar algum equívoco interpretativo, por exemplo, as correções, repetições saneadoras, as paráfrases, entre outras;

ii. estratégias metaenunciativas, por meio das quais o locutor reflete sobre a sua própria enunciação, isto é, o sujeito se torna comentador do seu próprio discurso;

iii.estratégias metapragmáticas ou modalizadoras, que têm por objetivo introduzir atenuações, comentários a respeito dos enunciados produzidos, com vista à preservação das faces, já que a denúncia do mal-entendido pode representar uma ameaça à face do interlocutor.

No que respeita a essas últimas estratégias, cabe destacar que a denúncia feita pelo interlocutor da posição três, pode se apresentar de forma mais ou menos explicita, dependendo de diferentes fatores. Muitas vezes há razões que demandam do falante de T3 uma atenuação de sua denúncia, para evitar, por exemplo, que a imagem social do falante do turno denunciado seja posta em risco. Outras vezes, ao contrário, a denúncia é bem explícita e, até mesmo, ríspida e deselegante, quando não ofensiva, como a que se mostrou no exemplo acima. Também as correções que ocorrem neste terceiro turno têm diferentes formulações. Algumas são sutis, consistindo em discreta reformulação parafrástica do enunciado de referência, geralmente em situações que demandam denúncias atenuadas. Outras são diretas e evidentes, quase sempre acompanhadas da explicitação do equívoco, comuns em contextos em que os interlocutores publicamente defendem suas posições em relação a um tema em foco.

Essas questões que envolvem atenuações e manifestações de cortesia ou mesmo de descortesia na denúncia e na solução de mal-entendidos implicam, no dizer de Goffman (1967, p. 12) um trabalho de imagem (face work). Afirma o autor que, por meio do trabalho de face ou atividade de imagem, todo indivíduo pode "neutralizar 'incidentes', ou seja, eventos cujas implicações simbólicas efetivamente ameacem a imagem".

Brown e Levinson (1987), na esteira de Goffman, partem do princípio de que todos os membros da sociedade possuem duas faces, a face positiva e a face negativa. Entendem por face positiva a imagem que o indivíduo deseja para si na interação com os outros. Representa o desejo de aprovação, de apreciação e reconhecimento individual. Já a face negativa constitui-se de elementos que promovem e mantêm a autonomia do indivíduo em seu âmbito de ação; é relativa à autopreservação, desejo de 
não imposição, de reserva de território pessoal, de liberdade de ação.

Numa interação comunicativa, essas faces podem ser mantidas ou valorizadas e, também, podem ser ameaçadas. Para os autores, a maioria dos atos de linguagem que são produzidos nas conversas cotidianas são potencialmente ameaçadores para uma das faces e, por conseguinte, podem pôr em perigo a imagem pública dos interlocutores, criando um sério risco para o bom desenvolvimento da interação. Por exemplo, críticas, acusações, insultos, interrupções e refutações ameaçam a face positiva do indivíduo, enquanto as ordens, os pedidos, os conselhos põem em risco a sua face negativa. Em sentido contrário, manifestações de cortesia suavizam ou neutralizam as ameaças.

Kerbrat-Orecchioni (2005) enfatiza que as faces são, ao mesmo tempo e contraditoriamente, o alvo de ameaças e o objeto de um desejo de preservação e, por esse motivo, a interação verbal mobiliza práticas, internalizadas pelos usuários da língua como verdadeiras normas culturais para o convívio harmonioso, que estimulem respeito à face dos interlocutores.

No monitoramento do mal-entendido do exemplo apresentado acima, o interlocutor C, em T4, ameaça, por um lado, a sua face positiva ao reconhecer sua interpretação equivocada do enunciado e ao pedir desculpas para $\mathbf{A}$; por outro, ao dar razão a este pela denúncia feita, promove-lhe a face positiva. Acresça-se que, apesar do fato de o falante pedir desculpas e reconhecer seu erro ponha em risco sua face na interação, na perspectiva dos valores sociais, essa postura beneficia a sua imagem, já que admitir seus próprios erros é um comportamento sancionado positivamente pela sociedade.

Portanto, na acusação de um equívoco de compreensão, espera-se que o enunciador tome precauções, procure cumprir o que dele se espera: que seja minimamente polido, já que essa denúncia constitui um risco para o interlocutor, que pode se sentir humilhado, ofendido, criticado; daí a necessidade de utilizar estratégias compensatórias como as atenuações e as manifestações de cortesia. Em um contexto de vulnerabilidade da imagem, lembram Brown e Levinson (1987), é provável que qualquer participante procure evitar os atos que ameacem a face, ou empregue determinadas estratégias para minimizar essa ameaça.

Retomando as considerações teórico-metodológicas até aqui feitas, podemos, agora, discriminar as principais categorias que irão, a seguir, orientar a análise de passagens interacionais do Twitter, em que ocorrem mal-entendidos. Nelas, então, verificaremos, não necessariamente nesta ordem: a) características gerais definidoras da oralidade conceptual do diálogo; b) a estrutura da dinâmica interacional no monitoramento dos mal-enten- 
didos; c) os fatores que os desencadeiam; d) os procedimentos metadiscursivos adotados para resolvê-los; e) o trabalho de face realizado nas ações de denúncia e de encaminhamento da solução.

\section{Os mal-entendidos em interações no Twitter}

Inicialmente, fazemos uma breve caracterização da rede social digital Twitter, uma vez que, em boa parte, os traços configuradores das interações em análise decorrem dessa caracterização. Trata-se de um ambiente na internet, que permite aos usuários postar mensagens e receber atualizações pessoais de outros contatos, em textos relativamente curtos. Em 2017, essa rede social estendeu seu clássico limite de 140 caracteres por mensagem para 280 caracteres, com o intuito de levar os interlocutores à melhor compreensão das mensagens.

Além da mensagem com até 280 caracteres, os usuários também podem postar fotos ou GIFs (Graphic Interchange Format), que se pode traduzir por formato para intercâmbio de gráficos, isto é, pequenas animações ou imagens em cores compactadas em um só arquivo. Essas postagens são conhecidas como tweets, palavra da língua inglesa significando "pio do passarinho". Ela simboliza as pequenas mensagens que se acumulam na timeline (página inicial dos usuários do Twitter, em que as publicações apa- recem em ordem cronológica). A partir desse conceito, foi desenvolvido também o logotipo da rede social: um pássaro azul, que representa justamente a comunicação por meio de tweets, ou seja, "pios".

Com 330 milhões de usuários ativos por mês ${ }^{1}$, o Twitter serve, nas palavras de Santaella e Lemos (2010, p. 66), como

[...] um espaço colaborativo no qual questões, que surgem a partir de interesses dos mais microscópicos aos mais macroscópicos, podem ser livremente debatidas e respondidas.

Neste ambiente virtual, é possível enviar e receber mensagens, como também replicar uma determinada publicação (retweet), dando o devido crédito ao seu autor original.

A nosso ver, o Twitter se apresenta como uma importante plataforma de informação, que permite divulgar notícias em tempo real a milhares de pessoas conectadas no mundo, bem como estabelecer uma aproximação entre perfis públicos, de diversas esferas de atuação, e seus seguidores. Essa rede social possibilita conhecer opiniões e tomadas de posição de seus participantes e torna-se particularmente atraente aos usuários, por oferecer um grande número de recursos e possibilidades de interação.

O estudo das interações no Twitter torna-se especialmente relevante, uma vez que nesse ambiente interativo virtual o compartilhamento de ideias e pontos de vista tende a favorecer, na 
dinâmica social da rede, momentos que solicitam dos participantes um esforço na negociação de conflitos e no estabelecimento de algum nível de harmonia em suas conversações digitais. É precisamente por isso que o Twitter oferece aos pesquisadores uma oportunidade sem precedentes de observação de comportamentos e análise de interações, num cenário contemporâneo de comunicação, em que é possível testar hipóteses e recrutar com eficiência participantes dos mais diversos perfis.

É oportuno dizer ainda que, com as inovações trazidas pelas tecnologias de informação e comunicação, a constituição da escrita modificou-se, ao incorporar nos textos elementos paralinguísticos e componentes semióticos que criam efeitos de oralidade, de realidade e simulam um sentido de proximidade entre os interlocutores. No Twitter, como em outros ambientes virtuais, predomina a utilização de uma linguagem informal, de redução de palavras, de abreviações, além dos emoticons (emotion: emoção + icon: ícone), recursos que exploram, no contexto digital, diferentes emoções ou procuram transmitir o estado psicológico dos interlocutores.

Desse modo, consideramos que as práticas discursivas mediatizadas pelos suportes técnicos de comunicação possuem características peculiares que demandam nossa atenção. O contexto virtual nos força a pensar sobre esses fenômenos e, consequentemente, a re- considerar questões teóricas tradicionais (SALIÉS; SHEPHERD, 2013).

Movidos por essa perspectiva, analisaremos, a seguir algumas interações do Twitter em que ocorrem mal-entendidos. Elegemos conversações digitais, constituídas de tweets selecionados a partir de uma amostra de contas verificadas ${ }^{2}$, cujos perfis são qualificados como figuras públicas (jornalistas, políticos, celebridades, entre outros).

(1)

Usuário A: "Enxerga a situação do Brasil, cara. Enquanto tem gente morrendo a rodo, eles estão preocupados com volta do futebol. Se você não consegue enxergar a gravidade disso, sinto muito" 18/06/2020, 23h41. Tweet.

Usuário B: "Quem tem q se preocupar com a saúde é o presidente, sec de saúde... Ministros Não o Gabigol, arrascaeta, eles só estão trabalhando, como eu e vc. E contribuindo com as pessoas q ficam em casa na quarentena e poder se distrair um pouco. Futebol é um bem sim. Psicologicamente." 18/06/2020, 23h50. Tweet.

Usuário A: "Quando eu me referi a pessoas estarem preocupadas apenas com a volta do futebol, eu não me referi aos jogadores porque isso não cabe a eles decidirem. Me referi aos verdadeiros responsáveis por pensarem apenas no próprio bolso" 19/06/2020, 3h06. Tweet.

Usuário A: "Esses caras estão pouco se importando com a saúde dos envolvidos na partida e com o risco de contribuírem na transmissão da doença, só querem saber do dinheiro que eles não podem perder" 19/06/2020, 3h06. Tweet.

Fonte: disponível em: https://twitter.com/xxxxxxxx/status/1273810456130588675. Acesso em: 22 jun. 2020. 
Inicialmente, observe-se o caráter oral da interação, ainda que ela se realize, medialmente, por escrito. É a essa percepção de oralidade que chamamos de oralidade conceptual. São vários os traços que evocam o diálogo face a face: a alternância de turnos; a interpelação do interlocutor, como se estivesse em relação face a face com ele (Enxerga a situação do Brasil, cara); o léxico do cotidiano, sem uso de termos que sejam próprios de jargões especializados; o predomínio absoluto da sintaxe conversacional, com períodos simples e frases nominais; a redução de palavras - $q$ (que), vc (você) -, que, de certa forma sugere a fluidez e a espontaneidade das manifestações faladas. É evidente que, por mais oralizado que seja o diálogo escrito, ele não se equivalerá, em suas características, ao falado. É por isso que falamos, anteriormente, que não se trata de definir se um gênero é oral em oposição a outro escrito, como se escrita e fala fossem categorias dicotômicas, mas sim de estabelecer o seu grau de oralidade ou de "escrituralidade". Nesse sentido é indiscutível que o diálogo aqui em observação tem alto grau de oralidade, na medida em que muito se aproxima de uma conversa fortuita do cotidiano, que seria o protótipo de uma interação oral. ${ }^{3}$

Do ponto de vista da estrutura da dinâmica interativa, constata-se a estrutura padrão concernente ao monitoramento do mal-entendido. $\mathrm{Na}$ posição
1, no turno de referência, o Usuário $\mathbf{A}$ aponta para a gravidade do fato de os dirigentes de clubes estarem preocupados para a volta do futebol, num momento, em que o país ainda assiste a um grande número de mortes. Na posição 2 , o Usuário B explicita a sua interpretação do enunciado de A. Nesse sentido, depois de dizer que o cuidado das questões de saúde caberia ao presidente, aos secretários e aos ministros, faz a defesa do trabalho dos jogadores como se eles tivessem sido o alvo de crítica de $\mathbf{A}$. Na posição três, o Usuário A denuncia, explicitamente, a leitura equivocada de $\mathbf{B}$, afirmando que sua crítica não dizia que os jogadores estavam preocupados com o futebol em meio à pandemia, mas sim os "os verdadeiros responsáveis”, numa referência clara aos dirigentes dos clubes, cujos interesses unicamente focalizariam 0 dinheiro. Por fim, o diálogo se encerra com uma quarta posição, turno em que o Usuário B não só concorda prontamente com a denúncia e a explicação de seu interlocutor, mas também não move uma única palavra em defesa de sua interpretação denunciada por $\mathbf{A}$.

No que concerne aos fatores que desencadearam o mal-entendido, fica evidente, com base na denúncia feita por $\mathbf{A}$, que se trata, por parte de $\mathbf{B}$, de um equívoco de percepção do alvo da crítica. Enquanto A disse ter focalizado os dirigentes, $\mathbf{B}$ entendeu ele ter visado os jogadores. A razão desse equívoco está 
num problema de coesão referencial, no primeiro turno da interação. Nele A afirma que "eles estão preocupados com volta do futebol", sem apresentar o referente de "eles". Se efetivamente esse referente não foi anteriormente definido na interação, a equívoco de $\mathbf{B}$ não só se justifica, como também poderia ter sido usado como argumento para sustentar a sua leitura.

Por fim, no que se refere ao trabalho de face, a interação se desenvolve numa linguagem direta e objetiva sem atitudes agressivas de algum dos interlocutores, mas também sem acionar recursos de atenuação destinados a minorar o risco de perda da face. Interações desse tipo revelam um contrato interacional de relações entre indivíduos em ambiente público, que se relacionam de igual para igual. Se algum comentário pode ser feito sobre o trabalho de imagem nesse diálogo, ele é referente ao turno da posição 4. Como vimos, a concordância de $\mathbf{B}$ com A não deixa de ser um reconhecimento de que este estava certo e aquele equivocado. Nesse sentido, $\mathbf{B}$ pôs em risco a sua própria face positiva e valorizou a de seu interlocutor por ter-lhe dado razão.
(2)

Usuário A: "Doar? Um bandido entra na sua casa, rouba tudo o eu você tem, mata pessoas da sua família, destrói o seu espaço emocional, memórias, depois ele volta e diz que vai deixar um dinheirinho para você recomeçar a vida. Que bandido caridoso!" 29 de jan.

VEJA 28 de jan

"Vale anuncia que irá doar $\mathrm{R} \$ 100$ mil a cada família de morto em tragédia".

Usuário B: (Em resposta a Usuário A)

"Eles deixaram bem claro que irão pagar as indenizações caso a caso. (Só para informar quem só leu a manchete). Sim, as famílias precisam de dinheiro agora. Os processos judiciais das indenizações demoram, nossa justiça é lenta, a tragédia de Mariana não foi resolvida". 29 de jan.

Usuário C: "Excelente Patrícia! Fico triste ao ver um Padre da minha santa igreja Católica promovendo discórdia e talvez até sentimento de culpa nas pessoas que perderam entes queridos e agora vão receber esta ajuda financeira pra tocar suas vidas :(" 29 de jan.

Usuário A: "Elias, você entendeu errado. Eu disse que não é doação. Doar é gesto gratuito de quem não tem obrigação de fazer. Não é o caso". 29 de jan.

Usuário C: Talvez foi o termo "jurídico" que usaram, mas o Padre tem razão. No mais entendo que não devo julgar, apenas rezar para que Deus conforte o coração das famílias e que elas recebam este valor, seja o nome que queiram dar..." 29 de jan.

Fonte: disponível em: https://twitter.com/pefabiodemelo/ status/1090170064807043072. Acesso em: 03 out. 2019. 
O primeiro turno, na posição 1, apresenta um tweet construído a partir de uma manchete publicada em um perfil institucional (revista Veja). O usuário $\mathbf{A}$ faz uma crítica contundente à mineradora Vale, identificando-a com um bandido, um "bandido caridoso" em sua ironia, por ter destruído, com a tragédia de Brumadinho (Minas Gerais), a vida e os sonhos de pessoas, e por vir fazer, agora, uma doação de 100 mil reais. Na sequência, na posição 2, o usuário $\mathbf{B}$ contesta essa crítica, afirmando que a Mineradora sabe de suas obrigações indenizatórias, fato que só não seria conhecido por quem unicamente lê as manchetes. Além disso, B sustenta ser a doação referida uma ajuda destinada a cobrir necessidades imediatas, já que os processos indenizatórios judiciais demoram.

Alia-se a $\mathbf{B}$, ainda nesta posição 2, o usuário $\mathbf{C}$, que lamenta (Fico triste), em tom muito irônico, "ver um Padre da minha santa igreja Católica promovendo discórdia" e "talvez até sentimento de culpa" nas pessoas, que se veem obrigadas a aceitar a doação.

É neste momento, na posição 3 , que retorna o interlocutor da posição 1 para se dirigir a $\mathbf{C}$, dizendo ter sido equivocada sua leitura, denunciando, portanto, o mal-entendido. Na percepção de $\mathbf{A}$, seu interlocutor não se apercebeu do fato de que a Vale fez a doação por obrigação e não de forma gratuita. Somente esta for- ma teria constituído, em sua concepção, uma doação.

Por fim, na posição 4, $\mathbf{C}$ dá razão a A (o Padre tem razão), mas não deixa de insinuar certa ironia em relação ao interlocutor, quando afirma que não lhe cabe julgar, deixando a entender que a manifestação de $\mathbf{A}$ foi um julgamento.

O Gráfico 3 explicita a dinâmica organizacional dos turnos do segmento analisado:

Gráfico 3 - Dinâmica organizacional dos turnos

\begin{tabular}{|l|l|}
\hline Posição 1 & -Turno A - enunciado de referência \\
\hline Posição 2 & $\begin{array}{l}\text {-Turno } \mathrm{B} \text { - interpretaçáo do enunciado de } \mathrm{A} \\
\text {-Turno } \mathrm{C} \text { - apoio à interpretação feita por } \mathrm{B}\end{array}$ \\
\hline Posição 3 & $\begin{array}{l}\text {-Turno } \mathrm{A} \text { - denúncia e solução do mal-entendido } \\
\text { na } 2^{\mathrm{a}} \text { posição }\end{array}$ \\
\hline
\end{tabular}

Fonte: elaboração dos autores.

Observa-se que a dinâmica organizacional apresenta duas variações em relação à estrutura padrão do mal-entendido. A primeira concerne à posição 2 , em que $\mathrm{C}$ ratifica a opinião de $\mathbf{B}$, ambos convergindo para a mesma interpretação do enunciado de $\mathbf{A}$, o que implica que a subsequente denúncia do mal-entendido de $\mathbf{A}$ atinja os pontos de vista de ambos, ainda que só faça referência à fala de C. Outro aspecto distintivo em relação à estrutura padrão é a posição 4, que é frequente, particularmente em interações públicas, situação em que o falante tem a necessidade de se justificar para salvar a sua face. Nela, o interlocutor $\mathbf{C}$ se manifesta sobre o dito na posição 3 , 
em geral concluindo a sequência interativa centrada no mal-entendido.

$\mathrm{O}$ fator determinante do mal-entendido, conforme já apontamos, foi, na alegação de $\mathbf{A}$, uma interpretação divergente do sentido de "doar". Para $\mathbf{B}$ e $\mathbf{C}$, mesmo que feita por obrigação, a ajuda de 100 mil reais foi uma doação. Para A, no entanto, doação há somente quando ela é espontânea e gratuita. Constate-se, contudo, que esta interpretação só se tornou explícita na fala de $\mathbf{A}$ na posição 3 , pois em seu turno, na posição 1 , ela não se evidencia. Os interlocutores, portanto, foram induzidos a sua leitura por problemas de formulação do turno inicial do diálogo.

Bem que A poderia ter pedido desculpas a eles por esse fato e, só então, ter denunciado o mal-entendido e apresentado a sua versão do sentido de "doar". No modo como se expressa (Elias, você entendeu errado), revela arrogância $\mathrm{e}$ descortesia, atingindo a face positiva do interlocutor C. Este, mesmo com um argumento disponível para justificar sua interpretação, assumiu o equívoco, pondo em risco a sua face positiva (mas o Padre tem razão). Ainda sobre o trabalho de face na interação, cabe ainda registrar duas ironias que têm por alvo o usuário A: um é de B, na posição 2, ao dizer "Só para informar quem só leu a manchete"; outra é de C, na posição 3 , quando fala "Fico triste ao ver um Padre da minha santa igreja Católica”. Ironias, em geral, são descorteses, pondo em risco severo a face positiva do interlocutor.

Usuário A: "Talvez seja tarde para salvar livrarias e jornais impressos, assim como é tarde pra ressuscitar a indústria fonográfica e as lojas de discos. Quanto mais cedo aceitarmos e entendermos a mudança, mais cedo colonizaremos esse território digital com informação de qualidade." 03/11/2018, $10 \mathrm{~h} 47$. Tweet.

Usuário B: "Eu não consigo... tentei ir pra essa mundo digital, mas nada substitui o cheiro e o contato com as páginas de um livro. Dói em mim ver livrarias fechando." 03/11/2018, 13h59. Tweet.

Usuário A: "Não me refiro só a e-books e e-readers. Me refiro a repensar a maneira e os canais para divulgar ciência e notícias. Os portais dos grandes jornais são pagos. Enquanto isso, a massa se 'informa' com notícias falsas no WhatsApp que é gratuito." 03/11/2018, 18h18. Tweet.

Usuário B: “É verdade. Acho mesmo que deveria ser repensado o sistema de leitura dos sites de notícias." 03/11/2018, 18h54. Tweet.

\footnotetext{
Fonte: disponível em: https://twitter.com/xxxxxxxx/status/1058717308020031488. Acesso em: 05 nov. 2018.
}

No primeiro turno, enunciado de referência, o usuário $\mathbf{A}$ expõe o tema de que trata a interação em curso: diante do fechamento de livrarias e jornais impressos determinado pelo crescente domínio de similares digitais, quanto mais cedo aceitarmos os fatos, melhor supriremos o território digital com informação de qualidade. Em comentário subsequen- 
te, na posição 2, o usuário $\mathbf{B}$ lamenta 0 fechamento das livrarias e confessa não se adaptar ao mundo digital. A seu ver, "nada substitui o cheiro e o contato com as páginas de um livro". A esse comentário retruca $\mathbf{A}$, na posição 3 , dizendo que sua intervenção não se limitava a "e-books e readers", mas tinha em vista uma estruturação dos canais digitais de forma que pudessem viabilizar a todos o acesso à ciência e à notícia, sem que a grande massa ficasse à mercê das notícias falsas das redes sociais, e só os que pudessem pagar as assinaturas tivessem acesso a jornais. Fica dessa forma denunciado que $\mathbf{B}$ captou só um aspecto do enunciado de referência, quando, então, incorreu no mal-entendido. Por fim, na quarta posição, B concorda com a correção feita por seu interlocutor (É verdade), vindo-lhe ao encontro, na medida em que propõe que sejam repensados os portais de notícias. Repete-se, assim a estrutura padrão no monitoramento do mal-entendido, acrescida da quarta posição, em que o interlocutor responsável por ele de alguma forma sanciona positivamente a denúncia e o procedimento de correção.

No que respeita ao trabalho de face dos interlocutores, cabem as seguintes observações. Na primeira posição, A formula seu turno na forma de uma opinião, suscetível, portanto, de ser questionada, já que o introduz por um advérbio de dúvida ou incerteza, que, nas interações costuma ter a função de atenuar o dito pelo sujeito. A ausência desse atenuador - como seria em $\hat{E}$ tarde para salvar livrarias... - intensificaria o dizer do sujeito, conferindo lhe tom dogmático e categórico, próprio de discursos arrogantes, que poderia levar o interlocutor tanto à intimidação em lhe responder, quanto à igual insolência na apresentação de uma opinião contrária. Da forma, no entanto, como $\mathbf{A}$ abriu seu turno, $\mathbf{B}$ sentiu-se à vontade para emitir sua opinião na posição 2 , ainda que nela só tenha contemplado um aspecto do enunciado de seu interlocutor. Para denunciar essa leitura parcial, A, na posição 3, mais uma vez se apresenta como um enunciador atenuado. Não o seria se, por exemplo, tivesse dito "Não me refiro a e-books e a readers", sem o modalizador "só". Com ele, como marcador de pressuposição, $\mathbf{A}$ admite que se refere também a eles em seu enunciado e que, por isso, $\mathbf{B}$ tem, ao menos em parte, razão na sua observação. O marcador tem, então, forte presença atenuadora no enunciado de A, na medida em que admite ser a intervenção do interlocutor pertinente na discussão. Sem ele, a face positiva de $\mathbf{B}$ ficaria fortemente atingida, já que implicaria excluir sua fala do tema em foco. Por fim, pode-se reconhecer que essa forma de enunciação atenuada de A, contribuiu para a pronta concordância de $\mathbf{B}$ (É verdade), na posição 4 , e na valorização da face positiva de $\mathbf{A}$. 


\section{Considerações finais}

Tivemos com este estudo o propósito de colocar em foco a compreensão em interações informais do cotidiano, desviando-nos, assim, dos textos de caracterização mais formal, em cujo âmbito, em geral, a temática da compreensão e da interpretação é estudada. Nessa perspectiva, restringimos nosso enfoque aos problemas de compreensão, mais especificamente, aos mal-entendidos, concebidos como instâncias inerentes à produção de sentidos nas interações, constantemente determinada pela imprevisibilidade da evolução das negociações entre interlocutores. O estudo dos problemas de compreensão tem ocorrido, historicamente, como vimos, no âmbito da análise das interações face a face. Partindo dos fundamentos produzidos nesse campo, resolvemos estendê-los à investigação de interações nas redes sociais, mais especificamente às realizadas no Twitter. A incorporação desses fundamentos para estudar interações que, na verdade, são escritas, se baseou em outro conceito de oralidade, a oralidade conceptual, segundo a qual essas interações, ainda que medialmente escritas, são percebidas pelos usuários da língua como orais. Vimos, pelas descrições, que os interlocutores efetivamente se portam como falantes, ressalvadas, é claro, coerções próprias da formulação escrita. Nessa perspectiva, então, era de se esperar que o monitoramento dos mal-entendidos no Twitter ocorresse na forma como ele se revela nas conversas. Os poucos exemplos que analisamos expõem o mesmo padrão estrutural, com a denúncia e o encaminhamento da solução do mal-entendido na terceira posição, e, consequentemente, a sua inscrição na segunda. Os excertos interativos que observamos trazem todos uma quarta posição, na qual o interlocutor, em princípio, sanciona o enunciado de denúncia e de correção do problema. Esse fato sugere que se possa talvez integrar essa posição, a depender de mais análises, na estrutura padrão, ao menos como tendência. É claro que, em sentido estrito, ela é dispensável nessa estrutura. Quanto aos "gatilhos" responsáveis pelos mal-entendidos, eles são de diversas naturezas envolvendo aspectos lexicais (sentido de palavras), estruturação sintática (coesao referencial), particularidades argumentativas. As ações de denúncia e correção são também de diferentes ordens, convergindo, em geral, para um único procedimento, ou seja, na explicitação da denúncia já se resolve o mal-entendido. Um aspecto destacado que se revelou na análise, foi o trabalho de face dos interlocutores, marcado tanto por atenuações e manifestações de cortesia, com a decorrente valorização das faces, quanto por traços de descortesia, seja por enunciados depreciadores e desrespeitosos, seja 
por insinuações irônicas, resultando na ameaça às faces.

Por fim, gostaríamos ainda de apontar perspectivas que as interações no Twitter sugerem para desenvolver ações na escola, destinadas ao domínio de habilidades linguístico-discursivas nas comunicações em geral. Em primeiro lugar, mencionaríamos o próprio estudo dos problemas de compreensão e dos mal-entendidos, na forma como o fizemos aqui, procurando desvelá-los como objetos teóricos. Além disso, como ficou evidente nas análises, das interações no Twitter emergem interessantes tópicos, como, por exemplo, estratégias de eficiência argumentativa, razões que levam a argumentação a falhar, fatores responsáveis por equívocos de interpretação, procedimentos de reformulação e de correção de mal-entendidos. Mas o que mais nos chamou a atenção nas breves análise, foram as formas e atitudes sociodiscursivas que, se configuradas pela atenuação e a cortesia, tecem a harmonia, o respeito e a civilidade democrática no embate dialogal, não importando se ele é contratual ou polêmico; e se marcadas pela ausência de atenuadores e por manifestações descorteses, tendem a desumanizar as contendas, com o risco de impulsioná-las para a vala comum dos discursos de preconceito, intolerância e ódio, dos quais, infelizmente, as redes sociais estão saturadas. Mas isso é tema para outro estudo.

\section{The negociation of misunderstandings on the social network Twitter}

\section{Abstract}

In this paper, we set out to identify misunderstandings in a corpus of messages posted in an internet environment. We seek to describe how the interlocutors, through discursive linguistic strategies, operate in the organization of the written virtual text, in order to monitor the misunderstandings, in order to proceed with the approach of the subject in communication. For the development of this study, we selected digital conversations, or rather tweets produced by profiles qualified as public figures interacting with their followers, on the social network Twitter. In the corpus analysis, we observed that, in the event of misunderstanding, the interlocutors use metadiscursive procedures to try to solve these misunderstandings that jeopardize the success of the interaction. To support this work, we resort to the theoretical assumptions coming from Conversational Ethnomethodology and Interactional Linguistics. We intend to demonstrate with this study that the interlocutors mobilize different operations on the very act of saying, in an attempt to negotiate misunderstandings, in order to ensure understanding as well as a minimum of harmony in their discursive practices in the digital context.

Keywords: Interaction. Misunderstanding. Negotiation. Understanding. Twitter. 


\section{Referências}

ARDISSONO, L.; DAMIANO, R.; BOELLA, G. A. Computational Model of Misunderstandings in Agent Communication. Lecture Notes in Computer Science, v. 1321, p. 48-59, 1997.

BAKHTIN, M. Os gêneros do discurso. In: BAKHTIN, M. Estética da criação verbal. São Paulo: Martins Fontes, 2003. p. 261-306.

BAZZANELLA, C.; DAMIANO, R. The interactional handling of misunderstanding in everyday conversations. Journal of Pragmatics, n. 31, issue 6, p. 817-836, 1999.

BROWN, P.; LEVINSON, S. C. Politeness: some universals in language usage. Cambridge: Cambridge University Press, 1987 [1978].

CLARK, H. Using language. Cambridge: Cambridge University Press, 1996.

DEPPERMANN, A. Verstehen im Gespräch. In: KÄMPER, Heidrun; EICHINGER, Ludwig M. Sprache, Kognition, Kultur. Berlin; New York: Waler de Gruyter, 2008. p. 225261.

FIEHLER, R. Verständigungsprobleme und gestörte Kommunikation: Einführung in die Thematik. In: FIEHLER, R. (org.). Verständigungsprobleme und gestörte Kommunikation. Radolfzell: Verlag für Gesprächsforschung, 2002. p. 7-15.

FIORIN, J. L. Pragmática. In: FIORIN, José Luiz (org.). Introdução à linguística II: princípios de análise. São Paulo: Contexto, 2003. p. 161-185.

GOFFMAN, E. Interaction ritual: essays on face to face behavior. New York: Garden City, 1967.

HILGERT, J. G. (org.). A linguagem falada culta na cidade de Porto Alegre: materiais para o seu estudo. Diálogos entre informante e documentador. Porto Alegre; Passo Fundo: UFRGS; UPF, 1997.
HILGERT, J. G. (org.). A linguagem falada culta na cidade de Porto Alegre: materiais para o seu estudo. Diálogos entre dois informantes. Florianópolis: Insular, 2009.

KERBRAT-ORECCHIONI, J. Le discours em interaction. Paris: Armand Colin, 2005.

KINDT, W. Konzeptuelle Grundlagen einer Theorie der Verständigunsprobleme. In:

FIEHLER, Reinhard (org.). Verständigungsprobleme und gestörte Kommunikation. Radolfzell: Verlag für Gesprächsforschung, 2002. p. 17-43.

$\mathrm{KOCH}, \mathrm{I}$. Introdução à linguística textual: trajetórias e grandes temas. 2. ed. São Paulo: Martins Fontes, 2009.

KOCH, P.; OESTERREICHER, W. 30 Jahre "Sprache der Nälhe - Sprache der Distanz". Zu Anfängen und Entwicklung von Konzepten im Feld von Mündllichkeit und Schriftlichkeit. In: FEILKE, H.; HENNIG, M. (org.). Zur Karriere von "Nähe und Distanz": Rezeption und Diskussion des Koch-Oesterreicher-Modells. Berlim: Walter de Gruyter, 2016. p. 11-72.

KOCH, P.; OESTERREICHER, W. Gesprochene Sprache in der Romania: Französisch, Italienisch, Spanisch. 2. ed. atual. e ampl. Berlin; New York: de Gruyter, 2011 (1990).

KOCH, P.; OESTERREICHER, W. Schriftlichkeit und kommunikative Distanz. Zeitschrift für germanistische Linguistik, v. 35, p. 346-375, 2007.

SALIÉS, T.G.; SHEPHERD, T.G. Por uma Linguística da Internet. In: SHEPHERD, T. G.; SALIÉS, T. G. (org.). Linguística da internet. São Paulo: Contexto, 2013. p. 7-14.

SANTAELLA, L.; LEMOS, R. Redes sociais digitais: a cognição conectiva do Twitter. São Paulo: Paulus, 2010.

SCHEGLOFF, E. A. Repair after next turn: the last structurally provided defense of intersubjectivity in conversation. American Journal of Sociology, n. 97, p. 1295-1345, 1992. 
SCHEGLOFF, E.; JEFFERSON, G.; SACKS, $\mathrm{H}$. The preference for self-correction in the organization of repair in conversation. Languages, n. 53, p. 361-382, 1977.

WEIGAND, E. Misunderstanding: the standard case. Journal of Pragmatics, v. 31, issue 6, p. 763-785, 1999. 